\title{
Healthcare Access Among Cambodia's Poor: An Econometric Examination of Rural Care-seeking and Out-of-Pocket Expenditure
}

\author{
Robert John Kolesar ${ }^{1,2,3, *}$, Sambo Pheakdey², Bart Jacobs ${ }^{4,5}$, Rebecca Ross ${ }^{6}$ \\ ${ }^{1}$ The Palladium Group/Health Policy Plus, Phnom Penh, Cambodia \\ ${ }^{2}$ General Secretariat of the National Social Protection Council, Ministry of Economy and Finance, Phnom Penh, Cambodia \\ ${ }^{3}$ Centre d'Etudes et Recherche sur le Développement International (CERDI), Université Clermont Auvergne, Clermont-Ferrand, France \\ ${ }^{4}$ Deutsche Gesellschaft Fuer Internationale Zusammenarbeit (GIZ), Phnom Penh, Cambodia \\ ${ }^{5}$ Social Health Protection Network, Bonn, Germany \\ ${ }^{6}$ The Palladium Group, Washington D.C., United States
}

Email address:

robertkolesar@outlook.com (R. J. Kolesar)

${ }^{*}$ Corresponding author

\section{To cite this article:}

Robert John Kolesar, Sambo Pheakdey, Bart Jacobs, Rebecca Ross. Healthcare Access Among Cambodia's Poor: An Econometric Examination of Rural Care-seeking and Out-of-Pocket Expenditure. International Journal of Health Economics and Policy.

Vol. 4, No. 4, 2019, pp. 122-131. doi: 10.11648/j.hep.20190404.12

Received: September 26, 2019; Accepted: October 23, 2019; Published: October 30, 2019

\begin{abstract}
To inform efforts to improve Cambodia's social health protection system and advance universal health coverage, health care-seeking and out-of-pocket expenditure (OOPE) were assessed using the 2016 Cambodia Socioeconomic Survey data. This study focuses on the poorest wealth quintile who reside in rural areas- the primary target population of Cambodia's largest social health protection scheme, the Health Equity Fund (HEF). The study also estimates the proportion of poor with an Equity card which provides access to HEF benefits at public facilities. Overall, $76 \%$ of people who sought healthcare in the past 30 days went to private providers, paying, on average, US\$39.43 for treatment. About 18\% of patients first sought care from public facilities, paying, on average, US $\$ 38.15$. Though HEF aims to provide free healthcare for the rural poor, this analysis found that $67.2 \%$ of such patients seeking first care at public health facilities pay, on average, US\$11.61 after controlling for confounding factors. However, treatment expenditure among the rural poor is about $52 \%$ less compared to third wealth quintile patients $(\mathrm{p}<0.01)$. About $36 \%$ of people under the national poverty line do not hold an Equity card to access HEF benefits. Thus, we conclude that HEF is not yet fully reaching its intended impact of removing OOPE as a barrier to access among the poor. Finally, free access to healthcare should incentivize utilization of public services; however, this study was unable to isolate such an effect among patients from the poorest wealth quintile. Access to healthcare can be strengthened with policy directives focused on further reducing OOPE and addressing other challenges to improve patient demand for public services such as quality of care. Enrollment exclusion errors should be corrected by relaxing the eligibility criteria with population coverage expansion. In addition, health service access should be systematically monitored by integrating service utilization, OOPE, and quality indicators into national monitoring and evaluation systems.
\end{abstract}

Keywords: Universal Health Coverage, Social Health Protection, Out-of-Pocket Expenditure, Social Protection Policy, Cambodia, Vulnerability, Rural Poor

\section{Introduction}

\subsection{Background}

The Royal Government of Cambodia has established the reduction of poverty, vulnerability, and inequality as explicit policy goals in its National Social Protection Policy Framework (NSPPF) 2016-2025. The Framework aims to improve and expand existing social health protection schemes to achieve universal health coverage (UHC). UHC 
requires financial risk protection, access to quality essential health-care services and access to safe, effective, quality and affordable essential medicines and vaccines for all [1]. A study comparing the UHC service coverage index ${ }^{1}$ among 52 countries found Cambodia to have one of the highest disparities between the national average and the poorest wealth quintile [2].

To inform and advance Cambodia's national policy objectives to achieve UHC we examine rural healthcare access focusing on the poorest wealth quintile. Access to healthcare refers to the ease with which people can obtain needed health services, or the ability to use health services with financial risk protection [3-4]. Access has three dimensions: physical accessibility, financial affordability, and acceptability [4-6]. Quality, which includes structure, process, and outcomes is a core element for each dimension of healthcare access [7-8]. Care-seeking and Out-of-Pocket expenditure (OOPE) were assessed to understand provider choice as well as estimate the effect of the Health Equity Fund (HEF) on access to public services by improving financial affordability among the poor.

\subsection{Care-seeking and Out-of-Pocket Expenditure}

The assessment of health care-seeking can help to explain access inequities and evaluate demand and supply-side interventions [9-11]. Likewise, OOPE, a key aspect of financial affordability, can be a barrier to health service access and cause financial hardship [12]. Even relatively modest OOPE can cause indebtedness and impoverishment [13]. Recent data indicates that OOPE constitute approximately $60 \%$ of total health expenditure, implying a high risk for healthcare-related financial hardship [14]. Although OOPE is decreasing, international evidence suggests that to progress towards UHC requires the proportion to be about $30 \%$ [15-16].

\subsection{Health Equity Fund}

The HEF, Cambodia's largest social health protection scheme, established to improve access to healthcare for the poor, currently provides insurance to about 2.6 million poor people [17-18]. The scheme reimburses public health facilities for user fees ${ }^{2}$ normally paid by the patient with the aim of eliminating OOPE [19]. The HEF benefit package includes consultations, diagnostic tests, and medicines on the essential drug list. Beneficiaries are primarily identified using a nationwide ID Poor system. This system combines proxy means testing, using observable household characteristics and assets, and community-based targeting and issues an Equity card to households determined to be poor. The ID

\footnotetext{
1 The index is based on 16 indicators, which included four from each of the categories of reproductive, maternal, newborn, and child health; infectious disease; non-communicable diseases; and service capacity and access.

2 User fees are the fixed amounts that public health facilities charge patients for a service. These are the amounts that are reimbursed for Health Equity Card holders.
}

Poor system initially focused on rural areas and was only expanded to include urban areas beginning in 2016 [20].

An additional $5 \%$ of HEF beneficiaries are identified using a complementary post-identification process managed by public hospitals using a standard tool [20]. By 2015, HEF was expanded to reimburse services at all public health facilities in the country [17].

There is evidence of exclusion and inclusion errors related to the ID Poor system. The HEF presently covers about $16 \%$ of the country's population ${ }^{3}$. This is less than the proportion in the first quintile (20\%), but higher than the (2019) official national poverty rate of $12.5 \%$. A recently completed analysis found that less than $50 \%$ of Equity card holders are under the nation poverty line [21]. As half of Equity cardholders represent about $8 \%$ of the population, the exclusion gap equates to 4.5 percentage points - the difference between the official poverty rate and those officially classified as poor who hold a card. This means that about $36 \%$ of people under the national poverty line do not hold an Equity card. This is consistent with other evidence showing $30 \%$ of the poor are excluded from HEF [22].

According to the 2014 Cambodia Demographic and Health Survey (CDHS), an overwhelming majority of adults (aged $15-49$ years), $-84 \%$ of women and $87 \%$ of men, - do not have health insurance. HEF coverage was the most frequently reported health insurance: $11.8 \%$ of women and $8.5 \%$ of men. The largest proportion of those reporting HEF coverage was among the first and second quintiles: $67.8 \%$ among women and $66.8 \%$ among men [23].

\subsection{Health Provider Selection and Cost of Care}

The 2014 CDHS found that more than two-thirds (67.1\%) of household $(\mathrm{HH})$ members who were ill or injured in the past 30 days sought their first treatment in the private sector; $21.9 \%$ sought first treatment in the public sector, $4.5 \%$ in the non-medical sector (see Table 1), and 1.6\% outside the country. The mean cost of care (excluding transport) for first treatment was estimated at US\$48.76 for public care, US\$33.00 for private care, US\$8.54 for non-medical care, and US\$202.49 for treatment outside the country. The higher cost of public care, compared to private care, may be related to the illness severity or facility type.

\section{Methods}

\subsection{Data}

This study analyzed the nationally representative 2016 CSES data. The dataset contains information on demographic characteristics, housing, education, labor force, household income, consumption and healthcare for 2,289 rural households with 10,013 individuals, including 1,772 people who had sought healthcare in the past 30 days.

\footnotetext{
3 Based on 2019 mid-year population projection of 16.3 million from the National Institute of Statistics.
} 
Following the survey's categorization, 20 healthcare provider-type categories were consolidated into four principle provider types: private sector, public sector, nonmedical, and overseas (see Table 1).

Table 1. Provider Types and Sub-categories.

\begin{tabular}{ll}
\hline Provider Type & Sub-categories \\
\hline & Private hospital \\
& Private clinic \\
Private Medical Sector & Private pharmacy \\
& Home/office \\
& Home visit \\
& Other private medical \\
\hline & National hospital \\
& Provincial hospital \\
& District hospital \\
Public Sector & Health center \\
& Health post \\
& Rehabilitation center \\
\hline & Drug shop/market \\
& Kru Khmer/traditional healer \\
& Monk \\
Non-medical & Traditional Birth Attendant \\
& Other \\
\hline
\end{tabular}

Note: Overseas medical service has no sub-categories.

As there is no direct, reliable measure of HEF enrollment in the 2016 CSES; and, the primary HEF eligibility criterion is poverty, this analysis used first wealth quintile as a proxy for HEF eligibility. In addition, as ID Poor was only initiated in urban areas in 2016-2017, the analysis was restricted to rural areas.

\subsection{Statistical Methods}

First, this study assessed health service care-seeking by provider type and wealth quintile. Second, a multinomial logistic regression model was fit to estimate the incremental effect of wealth on the selection of provider-type. This approach models the log odds of multiple outcomes as a linear combination of the predictor variables. The Providertype regression model controls for: (1) distance to provider, proxied by transport costs; (2) consultation type (i.e. preventative or curative); (3) facility type (i.e. hospital or not); (4) OOPE; (5) patient age; and (6) patient age squared. The analysis tested other factors that could explain provider selection including care-seeking frequency, chronic illness, household size, as well as head-of-household employment category, education level, and sex; and, interaction terms were tested between all pairs of independent variables. These variables were excluded from the final model as they did not improve the fit as evaluated using the log ratio test, and Akaike and Bayesian information criteria [24].

Equation 1 expresses the final provider choice regression model.

$$
\begin{array}{r}
\text { First_Care_Provider_type }{ }_{i}=\mathrm{B}_{0}+\mathrm{B}_{1} \text { Effective_income }_{\mathrm{i}}+ \\
\mathrm{B}_{2} \text { Transport_Costs }_{\mathrm{i}}+\mathrm{B}_{3} \text { Consultation_type }_{\mathrm{i}}+ \\
\mathrm{B}_{4} \text { Facility_type }_{\mathrm{i}}+\mathrm{B}_{5} \mathrm{OOPE}_{\mathrm{i}}+\mathrm{B}_{6} \mathrm{Age}_{\mathrm{i}}+\mathrm{B}_{7} \mathrm{Age}_{\mathrm{i}}{ }_{\mathrm{i}}+\varepsilon
\end{array}
$$

generalized linear regression model (GLM) was fit (see Equation 2). GLM is appropriate for skewed (i.e., expenditure) data and avoids retransformation issues using a logged dependent variable [24]. The OOPE regression model controls for: (1) distance to provider, proxied by transport costs; (2) facility type (i.e. hospital careseeking or not); (3) chronic condition (i.e. having the reported illness for over one year); (4) frequency of care seeking (i.e., the number of times the patient sought care in the past 30 days); (5) patient age; and (6) head of household age. Finally, the analysis tested other factors that could explain the variation in OOPE, including healthcare service type (curative or preventive), patient age squared, household size, as well as head-of-household employment category, education level, and sex; and, interaction terms were tested between all pairs of independent variables. These variables were excluded from the final model as they did not improve the fit [24].

Equation 2 expresses the final OOPE regression model.

$$
\begin{array}{r}
\text { OOPE }_{\mathrm{i}}=\mathrm{B}_{0}+\mathrm{B}_{1} \text { Wealth_quintile }_{\mathrm{i}}+\mathrm{B}_{2} \text { Transport_costs }_{\mathrm{i}}+ \\
\text { B }_{3} \text { Facility_type }_{\mathrm{i}}+\mathrm{B}_{4} \text { Chronic_condition }_{\mathrm{i}}+ \\
\text { B }_{5} \text { Careseeking_frequency }_{\mathrm{i}}+\mathrm{B}_{6} \text { Patient_age }_{\mathrm{i}}+ \\
\mathrm{B}_{7} \mathrm{HH} \text { _head_age } \mathrm{i}_{\mathrm{i}}+\varepsilon
\end{array}
$$

This model was used to estimate the expected effect of wealth quintile on OOPE by adjusting OOPE to zero for all patients in the first quintile and reruning the fitted model. The diffence between the actual (i.e., coefficients estimated using unadjusted data) and expected effect (i.e., coefficients estimated using adjusted data) was then tested for significance [25].

In most household surveys, income is commonly underreported, vulnerable to random shocks, and possibly negative because investment is not depreciated [23]. For these reasons, expenditure data are generally considered more reliable than income data [26-28]. This analysis used consumption expenditure as effective income [14]. Income and consumption expenditure data were winsorized to transform values above the $99^{\text {th }}$ percentile to the $99^{\text {th }}$ percentile, limiting the influence of outliers [30]. Analyses were adjusted for sample design; Stata 15.1 was used for all data management and analysis [31].

\section{Results}

The survey data estimates that over three-quarters (76.5\%) of Cambodia's population resides in the rural areas; $23.5 \%$ live in urban areas (not shown). Figure 1 presents the proportional breakdown of the rural population by wealth quintile. In Cambodia's rural areas, over half of the population (52.9\%) are in the two lowest quintiles: $28.5 \%$ in the poorest quintile, and $24.4 \%$ in the second quintile.

Third, to estimate OOPE at public health facilities, a 


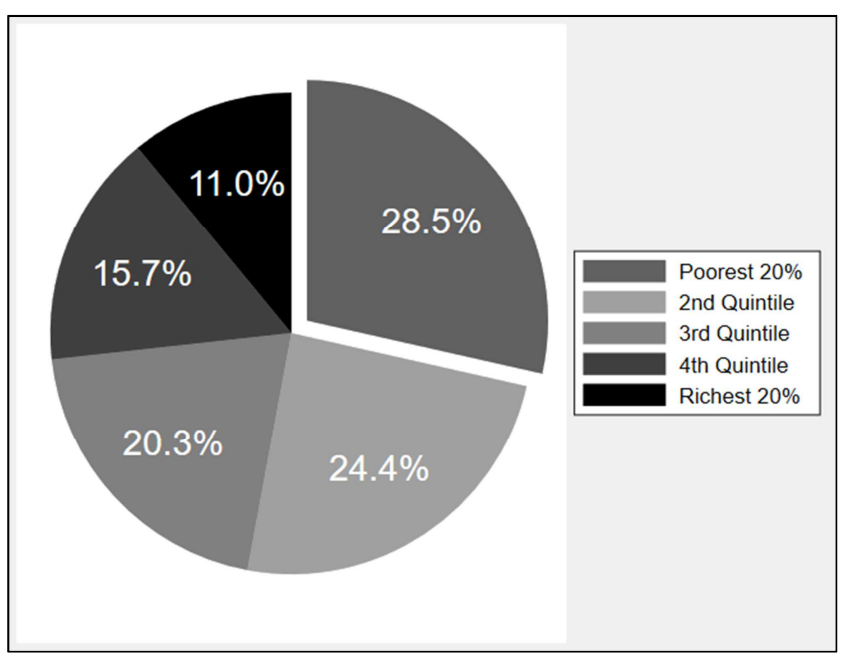

Figure 1. Rural Population Distribution by Wealth Quintile.

\subsection{Health Service Care-seeking}

Table 2 presents care-seeking summary statistics for key variables among rural residents as reported during the past 30 days. Overall, $16.8 \%$ of the rural population reported suffering from an illness or injury with $94.3 \%$ seeking care for that condition. Among those seeking care, the mean transport cost was US\$2.39 and illness duration 11.3 days. Under 5\% of those seeking care did so at a hospital (public or private). Over $22 \%$ identified the presenting illness as a chronic condition; and, $80.1 \%$ reported seeking curative care as opposed to preventive. Among patients seeking any care in the past 30 days, they reported doing so, on average, 1.78 times in that period. A secondary analysis of each variable by wealth quintile (not shown) only found transportation expenditure and illness duration to have statistically significant differences in the mean estimate among wealth quintiles. These differences were limited to a comparison between the poorest quintile and the richest.

Overall, $75.7 \%$ of rural patients used the private sector as their first point of contact for either curative or preventive health services. Only $17.8 \%$ first sought healthcare among public services compared to $5.4 \%$ from non-medical providers; and $1.1 \%$ outside of Cambodia (not shown). However, among the $80.1 \%$ of people seeking curative services, $81.3 \%$ went first to the private sector, $12.9 \%$ to the public sector, and $5.1 \%$ to non-medical providers (not shown). By contrast, among the $19.9 \%$ of people seeking preventive services, $55.9 \%$ went first to a private provider, $39 \%$ to a public provider, and $2.3 \%$ to a non-medical provider (not shown).

Table 2. Descriptive Characteristics of Key Careseeking Variables among Rural Residents.

\begin{tabular}{|c|c|c|c|c|}
\hline Variable & Type & Units & Point Estimate & $95 \%$ CI \\
\hline Illness or Injury & binary & Proportion sick or injured & $16.8 \%$ & $81.7-84.7 \%$ \\
\hline Seeking care & binary & Proportion of sick/injured seeking care & $94.3 \%$ & $91.1-96.3 \%$ \\
\hline Patient age & discrete & Mean years & 33.0 & 31.4-34.6 years \\
\hline Head of Household age & discrete & Mean years & 48.3 & 47.2-49.4 years \\
\hline Careseeking frequency & discrete & Mean times & 1.78 & 1.7-1.9 times \\
\hline Chronic condition & binary & Proportion chronic & $22.3 \%$ & $19.9-24.9 \%$ \\
\hline Distance to facility/ Transport costs & continuous & Mean USD & $\$ 2.39$ & $\$ 1.96-2.82$ \\
\hline Facility type & binary & Proportion seeking care at hospital & $4.6 \%$ & $3.8-5.6 \%$ \\
\hline
\end{tabular}

Among patients reporting more than one visit to a healthcare provider in the past 30 days, private sector utilization increased to $84.4 \%$ for the second visit, compared to $10.4 \%$ for the public sector, $4.2 \%$ for non-medical, and $1 \%$ for overseas (not shown).

Table 3 presents the marginal effects of the independent variables on health provider utilization for the first-time care visit, using adjusted predictions and controlling for all other covariates. Marginal effects show the change in probability when the predictor variable increases by one unit. After controlling for all other covariates, the adjusted probability of private sector care seeking was found to be $10.5 \%$ less among patients seeking preventive care relative to those seeking curative care $(\mathrm{p}<0.000)$. In addition, the probability of private sector care seeking increased by $0.1 \%$ for every dollar increase in OOPE $(\mathrm{p}<0.035)$, holding all other variables constant. For public care seeking, there was an estimated $0.3 \%$ increased probability in utilization for every dollar spent on transport $(\mathrm{p}<0.029)$; a $11.8 \%$ increase associated with preventive care seeking $(\mathrm{p}<0.000)$; a $33.8 \%$ increase among patients seeking care at a hospital $(\mathrm{p}<0.000) ;$ a $0.5 \%$ decrease in probability with every US $\$ 10$ increase in OOPE $(p<0.02)$; and a $0.3 \%$ decrease in public provider care seeking for every one year increase in patient age $(p<0.001)$, although that trend tapered off and reversed as patient age increased $(\mathrm{p}<0.004)$. The model did not identify any statistically significant factors associated with non-medical service seeking, although a statistically significant association with effective income was found (see below). As expected, care seeking overseas was associated with increased distance to provider/transportation costs $(0.01 \%$ for every additional dollar in transport expenditure) and was $16 \%$ less probable among patients seeking hospital care compared to nonhospital care. 
Table 3. Marginal Effects of Key Variables on Health Provider Utilization for First-time Care Visit among Rural Residents.

\begin{tabular}{|c|c|c|c|c|c|c|}
\hline Variables & dy/dx & Std. Err. & $\mathbf{t}$ & $P>t$ & {$[95 \%$ Conf. } & Interval] \\
\hline \multicolumn{7}{|c|}{ Private Sector } \\
\hline \multicolumn{7}{|l|}{ Wealth Quintile } \\
\hline Poorest & -0.018 & 0.033 & -0.55 & 0.586 & -0.083 & 0.047 \\
\hline Second & -0.030 & 0.031 & -0.98 & 0.325 & -0.091 & 0.030 \\
\hline Third (base) & - & - & - & - & - & - \\
\hline Fourth & -0.014 & 0.044 & -0.32 & 0.751 & -0.100 & 0.072 \\
\hline Richest & 0.041 & 0.044 & 0.94 & 0.346 & -0.045 & 0.127 \\
\hline Distance to provider & 0.000 & 0.006 & 0.01 & 0.995 & -0.012 & 0.012 \\
\hline Consultation type & -0.105 & 0.027 & -3.85 & $0.000 * * *$ & -0.158 & -0.051 \\
\hline Facility type & -0.123 & 0.071 & -1.72 & 0.086 & -0.262 & 0.017 \\
\hline OOPE & 0.001 & 0.001 & 2.12 & $0.035^{*}$ & 0.000 & 0.002 \\
\hline Patient age & 0.002 & 0.001 & 1.75 & 0.082 & 0.000 & 0.005 \\
\hline Patient age (squared) & 0.000 & 0.000 & -1.53 & 0.128 & 0.000 & 0.000 \\
\hline \multicolumn{7}{|c|}{ Public Sector } \\
\hline \multicolumn{7}{|l|}{ Wealth Quintile } \\
\hline Poorest & -0.004 & 0.026 & -0.14 & 0.889 & -0.055 & 0.048 \\
\hline Second & 0.024 & 0.026 & 0.94 & 0.349 & -0.027 & 0.075 \\
\hline Third (base) & - & - & - & - & - & - \\
\hline Fourth & 0.002 & 0.032 & 0.08 & 0.940 & -0.061 & 0.066 \\
\hline Richest & -0.003 & 0.041 & -0.08 & 0.940 & -0.083 & 0.077 \\
\hline Distance to provider & 0.003 & 0.002 & 2.20 & $0.029 *$ & 0.000 & 0.006 \\
\hline Consultation type & 0.118 & 0.020 & 5.80 & $0.000 * * *$ & 0.078 & 0.159 \\
\hline Facility type & 0.338 & 0.023 & 14.67 & $0.000 * * *$ & 0.293 & 0.383 \\
\hline OOPE & -0.0005 & 0.000 & -2.33 & $0.020 *$ & -0.001 & 0.000 \\
\hline Patient age & -0.003 & 0.001 & -2.96 & $0.003 * *$ & -0.005 & -0.001 \\
\hline Patient age (squared) & 0.0000 & 0.000 & 2.60 & $0.010 * *$ & 0.000 & 0.000 \\
\hline \multicolumn{7}{|c|}{ Non-medical } \\
\hline \multicolumn{7}{|l|}{ Wealth Quintile } \\
\hline Poorest & 0.021 & 0.020 & 1.08 & 0.280 & -0.017 & 0.060 \\
\hline Second & 0.014 & 0.018 & 0.79 & 0.432 & -0.021 & 0.049 \\
\hline Third (base) & - & - & - & - & - & - \\
\hline Fourth & 0.016 & 0.029 & 0.53 & 0.595 & -0.042 & 0.073 \\
\hline Richest & -0.026 & 0.016 & -1.65 & 0.099 & -0.057 & 0.005 \\
\hline Distance to provider & -0.004 & 0.007 & -0.66 & 0.511 & -0.017 & 0.009 \\
\hline Consultation type & -0.017 & 0.018 & -0.94 & 0.347 & -0.052 & 0.018 \\
\hline Facility-type & -0.056 & 0.042 & -1.32 & 0.187 & -0.139 & 0.027 \\
\hline OOPE & -0.001 & 0.001 & -1.34 & 0.182 & -0.002 & 0.000 \\
\hline Patient age & 0.001 & 0.001 & 1.21 & 0.229 & 0.000 & 0.002 \\
\hline Patient age (squared) & 0.000 & 0.000 & -0.90 & 0.367 & 0.000 & 0.000 \\
\hline \multicolumn{7}{|c|}{ Overseas } \\
\hline \multicolumn{7}{|l|}{ Wealth Quintile } \\
\hline Poorest & 0.000 & 0.007 & 0.06 & 0.953 & -0.014 & 0.014 \\
\hline Second & -0.008 & 0.007 & -1.14 & 0.254 & -0.021 & 0.006 \\
\hline Third (base) & - & - & - & - & - & - \\
\hline Fourth & -0.004 & 0.011 & -0.39 & 0.693 & -0.025 & 0.017 \\
\hline Richest & -0.012 & 0.010 & -1.19 & 0.234 & -0.032 & 0.008 \\
\hline Distance to provider & 0.001 & 0.000 & 2.36 & $0.019^{*}$ & 0.000 & 0.002 \\
\hline Consultation type & 0.003 & 0.004 & 0.76 & 0.447 & -0.005 & 0.011 \\
\hline Facility-type & -0.160 & 0.060 & -2.65 & $0.008 * * *$ & -0.278 & -0.041 \\
\hline OOPE & 0.000 & 0.000 & 1.84 & 0.067 & 0.000 & 0.000 \\
\hline Patient age & 0.000 & 0.000 & 0.68 & 0.495 & 0.000 & 0.001 \\
\hline Patient age (squared) & 0.000 & 0.000 & -0.90 & 0.371 & 0.000 & 0.000 \\
\hline
\end{tabular}

$* * * \mathrm{P}<0.001, * * \mathrm{P}<0.01, * \mathrm{P}<0.05$.

To more closely examine the associated marginal effects of income on provider choice, estimates were re-run replacing wealth quintile (categorical variable) with $\mathrm{HH}$ effective income (continuous). Figure 2 presents the predicted probabilities of healthcare seeking by provider type with $95 \%$ CIs after holding all other variables in the model constant. This approach revealed a small and statistically significant effect of income on healthcare provider choice for private and non-medical providers. The results show a statistically significant increase of
$0.9 \%(\mathrm{p}<0.046)$ in the probability of private provider utilization for every US\$100 increase in monthly effective income. Analysis also shows a statistically significant decrease in the probability of non-medical utilization, by $0.7 \%$ for every US $\$ 100$ in monthly effective income $(p<0.05)$. However, this decrease tapered off when income approached approximately $\$ 1,050$. No statistically significant change was detected in the adjusted probability of international care seeking with wealth quintile-likely a result of the relatively low representation in 
the sample. The downward trend for public sector use as income increases is not statistically significant.

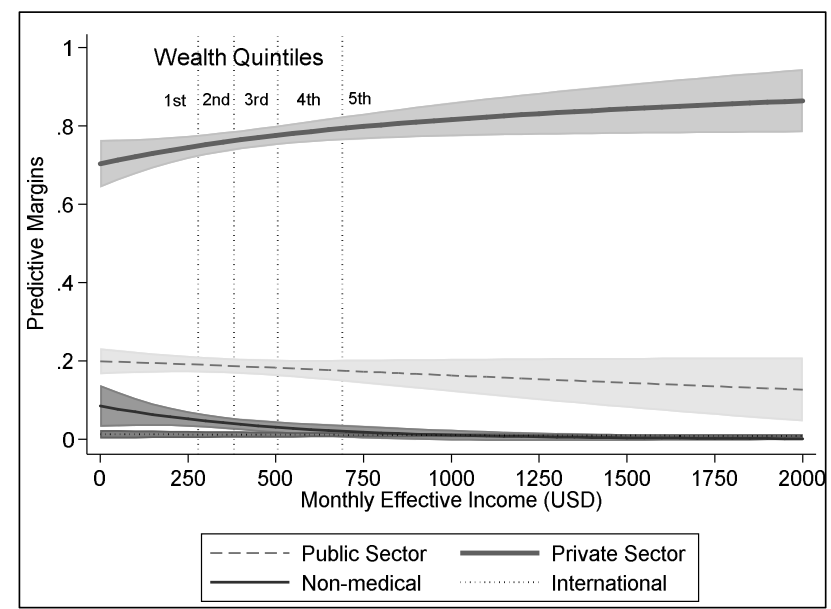

Figure 2. Predicted Probabilities of Healthcare Seeking by Provider Type.

Note: Figure 2 is truncated at $\$ 2,000$; however, the winsorized upper limit (i.e., $99^{\text {th }} \%$ ile) of monthly effective income is $\$ 3,800$.

\subsection{Out-of-Pocket Expenditure (OOPE)}

OOPE refers to the amount of money paid in the past 30 days for treatment which includes service costs, diagnostics, and medications; it does not include transportations costs. The weighted mean OOPE varies by provider type: US\$38.15 [95\% CI: $\$ 25.20-\$ 51.10$ ] for the public sector; US\$39.43 [CI: \$18.78-\$60.10] for the private sector; US\$5.82 [CI: \$2.80-\$8.84] for non-medical; and US\$232.59 [CI: \$88.93-\$376.24] for international care.

Among all patients seeking healthcare, only $15.4 \%$ reported not paying for the service; $77.8 \%$ of those not paying for service sought care in the public sector. In addition, $67.2 \%$ of people from the first quintile households who sought healthcare at a public facility reported paying, on average (weighted, unadjusted- i.e. no controlling covariates) \$10.84 [95\% CI: \$4.71-\$16.98]. By comparison, the average treatment expenditure among first quintile patients at private medical facilities was $\$ 9.50$ [95\% CI: \$8.01-\$11.00]. Among first quintile patients who sought services at a public facility, $30.9 \%$ reported the primary source of financing of their treatment to be their savings; $4.1 \%$ borrowed money, and $2 \%$ sold assets or household production in advance.

Over $86.1 \%$ of the second quintile patients paid for service when seeking care at a public facility, compared to 91.0 and $93.2 \%$ of patients in the third and fourth quintiles, respectively. All patients from the richest quintile reported paying for services.

Figure 3 shows the weighted, adjusted (i.e. controlling for all other covariates in the model) mean OOPE among patients seeking care at public health facilities by wealth quintile. After controlling for all other covariates, the poorest quintile was estimated to pay US\$11.61 [95\% CI: $\$ 5.99$ $\$ 17.22$ ], the second quintile US\$18.01 [CI: \$11.16-\$24.85], third quintile US\$24.16 [CI: \$13.38-\$34.94], fourth quintile US\$40.09 [CI: \$25.51-\$54.67], and richest quintile US\$55.27 [CI: \$31.96-\$78.58].

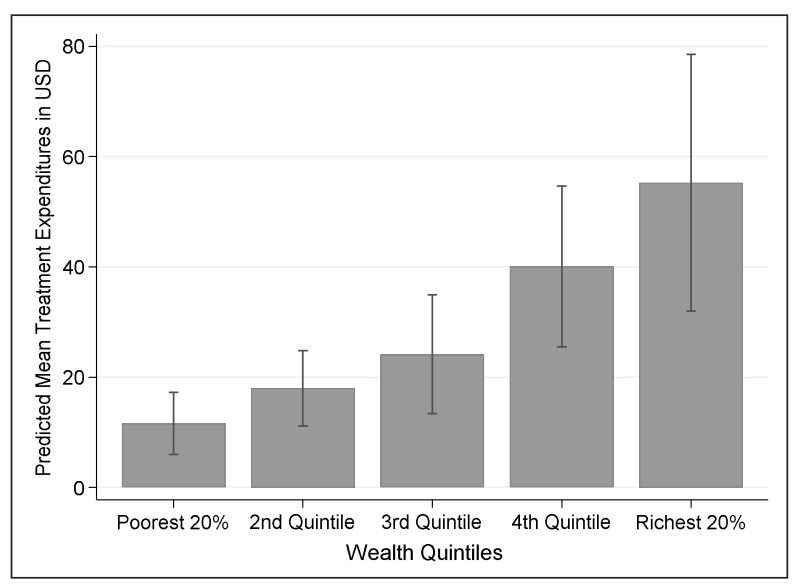

Figure 3. Adjusted Average OOPE at Public Health Facilities for Rural Residents by Wealth Quintile with 95\% Confidence Intervals.

Table 4 presents the regression coefficients from the actual and expected OOPE at public health facilities among HEF-eligible patients. Compared with third quintile patients, OOPE among the poorest quintile at public health facilities show a statistically significant $(\mathrm{p}<0.01)$ decrease, by about $52 \%[-.519=(\exp (-0.733)-1]$ holding all other covariates constant. OOPE were adjusted to zero for all patients in the first quintile to estimate the expected effect of HEF on OOP; this approach confirmed a $100 \%[-1.0=\exp (-7.601)-1]$ reduction in OOPE among the poorest quintile. The difference between the actual and expected reduction in OOPE is statistically significant $(\mathrm{z}<0.000)$. Note that this adjustment in the data did not statistically change the coefficients for any other variable in the model.

Table 4. Actual and Expected OOPE for Rural Residents at Public Health Facilities among First Quintile Patients.

\begin{tabular}{|c|c|c|c|c|c|c|c|c|c|}
\hline \multirow{3}{*}{ Dependent Variables } & \multicolumn{6}{|c|}{ Coefficients Explaining the Variation in OOPE } & \multirow{2}{*}{\multicolumn{3}{|c|}{ Differences (actual less expected) }} \\
\hline & \multicolumn{3}{|c|}{ Actual OOPE } & \multicolumn{3}{|c|}{ Expected OOPE } & & & \\
\hline & Coef. (B1) & $\begin{array}{l}\text { Std. } \\
\text { Err. }\end{array}$ & $\mathbf{P}>\mathbf{t}$ & $\begin{array}{l}\text { Coef. } \\
\text { (B2) }\end{array}$ & Std. Err. & $\mathbf{P}>\mathbf{t}$ & B1-B2 & $\mathbf{Z}$ & $|\mathbf{Z}|>\mathbf{1}$ \\
\hline \multicolumn{10}{|l|}{ Wealth quintile } \\
\hline Poorest & -0.733 & 0.28 & $0.010 * *$ & -7.601 & 0.20 & $0.000 * * *$ & 6.868 & 19.65 & $<0.000 * * *$ \\
\hline Second & -0.294 & 0.23 & 0.206 & -0.219 & 0.22 & 0.318 & -0.075 & -0.23 & 0.818 \\
\hline Third (base) & - & - & - & - & - & - & - & - & - \\
\hline Fourth & 0.506 & 0.24 & $0.038 *$ & 0.531 & 0.23 & $0.019 *$ & -0.025 & -0.08 & 0.936 \\
\hline Richest & 0.827 & 0.25 & $0.001 * * *$ & 0.926 & 0.24 & $0.000 * * *$ & -0.099 & -0.28 & 0.780 \\
\hline Distance to provider & 0.050 & 0.01 & $0.001 * * *$ & 0.037 & 0.010 & $0.000 * * *$ & 0.012 & 0.70 & 0.484 \\
\hline
\end{tabular}




\begin{tabular}{|c|c|c|c|c|c|c|c|c|c|}
\hline \multirow{3}{*}{ Dependent Variables } & \multicolumn{6}{|c|}{ Coefficients Explaining the Variation in OOPE } & \multirow{2}{*}{\multicolumn{3}{|c|}{ Differences (actual less expected) }} \\
\hline & \multicolumn{3}{|c|}{ Actual OOPE } & \multicolumn{3}{|c|}{ Expected OOPE } & & & \\
\hline & Coef. (B1) & $\begin{array}{l}\text { Std. } \\
\text { Err. }\end{array}$ & $\mathbf{P}>\mathbf{t}$ & $\begin{array}{l}\text { Coef. } \\
\text { (B2) }\end{array}$ & Std. Err. & $\mathbf{P}>\mathbf{t}$ & B1-B2 & $\mathbf{Z}$ & $|\mathbf{Z}|>\mathbf{1}$ \\
\hline Service frequency & 0.257 & 0.14 & 0.070 & 0.181 & 0.108 & 0.094 & 0.076 & 0.43 & 0.667 \\
\hline Facility type & 0.412 & 0.19 & 0.031 & 0.532 & 0.149 & 0.000 & -0.120 & -0.50 & 0.617 \\
\hline Chronic condition & 0.110 & 0.21 & 0.609 & 0.322 & 0.128 & 0.012 & -0.212 & -0.85 & 0.395 \\
\hline Patient age & 0.018 & 0.00 & $0.000 * * *$ & 0.015 & 0.003 & $0.000 * * *$ & 0.003 & 0.54 & 0.589 \\
\hline Head of $\mathrm{HH}$ age & -0.015 & 0.01 & $0.018 *$ & -0.014 & 0.005 & $0.006 * *$ & -0.002 & -0.23 & 0.818 \\
\hline Constant & 2.262 & 0.59 & 0.000 & 2.015 & 0.365 & 0.000 & 0.247 & 0.36 & 0.719 \\
\hline
\end{tabular}

$* * * \mathrm{P}<0.001, * * \mathrm{P}<0.01, * \mathrm{P}<0.05$.

Actual OOPE showed a statistically significant increase with distance to healthcare provider-by about $5 \%[0.051=$ $\exp (0.050)-1]$ for each additional US\$1 spent on transport; and patient age-by about $2 \%$ [0.018 = exp (0.018)-1] for every additional year of age. In addition, analysis showed a statistically significant effect of age of the head of household decreasing costs by about $2 \%[-0.015=\exp (-0.018)-1]$ for every additional year.

\section{Discussion}

\subsection{Limitations}

There are several limitations of this study. Foremost, the first quintile is an imperfect proxy for HEF eligibility. Because HEF eligibility is determined using a proxy means test with community validation, there is no income threshold that can be applied for analysis. This issue is further complicated by evidence of enrollment exclusion and inclusion errors as discussed above. In addition, the population proportion identified by ID Poor does not align with the official national poverty rate that is based on consumption with a monetary threshold. Nevertheless, there are several strong arguments to support the use of the first quintile as a proxy for HEF eligibility. First, a recently completed analysis found that about $90 \%$ of households targeted by ID Poor are classified as poor under a vulnerability line of 1.5 times the national poverty threshold [21]. The real 2016 value of this monthly per capita vulnerability threshold is estimated at US\$57.05.4 This is comparable to the upper effective income threshold of the first quintile which is US\$57.59. Second, the RGC's highlevel social protection policy objectives are to reduce and prevent poverty, vulnerability, and inequality; and, the goal of the HEF is to improve access to public healthcare among the poor by eliminating OOPE. As there is evidence demonstrating financial vulnerability among Cambodia's second and third quintiles relating to health expenditure, our focus only on the first quintile can be considered a conservative approach [32]. Moreover, transient poverty, or those moving in and out of poverty from income shocks, affects $40-52 \%$ of the population in rural Cambodia [33-34].

$4($ KHR $149524 * 150 \%) / 4100=\$ 54.70$ US per capita $*(1.01221(2015$ Consumer price inflation $) * 1.03045(2016$ Consumer price inflation $)=1.043)=$ $\$ 57.05$ US.
This analysis was also limited by the classification of only two types of health expenditure in the past 30 days: transport and treatment. Other limitations include the provider-type groupings. Private and public sector groupings include a variety of provider sizes, notably hospitals and clinics/health centers with different implications on OOPE that correlates with level of provider. Analysis by provider type sub-groups was explored, however the sample size was insufficient to support robust results. To address the issue, hospital careseeking (or not) was included as a binary control variable.

In addition, transport costs was used as a proxy for distance to health provider. However, many unobserved factors can affect transport costs such as available transport options including the procession or not of a personally owned vehicle, household disposable income, cash availability, agency of the caretaker or care-seeker to expend disposable income, and perceived illness severity.

The HEF benefit package includes consultation, diagnostic tests, and medicines on the essential drug list including chronic non-communicable diseases. However, due to limited drug stocks at public health facilities these patients tend to be provided with drug prescriptions to purchase such medicines. For example, a recently published study on hypertension and diabetes found that patients first sought medical treatment with modern allopathic medicine, and in most cases, medicines were purchased elsewhere [35]. To limit the influence of this potential confounding factor, chronic disease was used as a control variable.

\subsection{Interpretation}

The primary purpose of the HEF is to improve access to healthcare for the poorest through reimbursement of user-fee exemptions at public health facilities [17]. However, an examination of OOPE among the poorest quintile rural patients seeking first-time health service in the public sector reveals that $67.2 \%$ pay, on average, US $\$ 11.61$ [95\% CI: $\$ 5.99-\$ 17.22]$, after controlling for other factors. These findings are consistent with another recent assessment of spending for care seeking at public facilities [36]. OOPE among the first quintile poor at public facilities was found to be about $52 \%$ less compared to third quintile patients $(\mathrm{p}<0.01)$ after controlling for other factors. The difference between coefficients for the expected OOPE (zero) and actual among first quintile patients, was highly statistically significant $(\mathrm{p}<0.000)$. These findings are consistent with 
other studies that show HEF to be associated with reduced OOPE by about $57 \%$ among eligible poor people compared with non-poor people [37-38].

There are several possible explanations. First, as noted above, exclusion errors in the ID Poor system mean that only around $64-70 \%$ of the poor under the national poverty line are provided with an Equity card [21-22]. The postidentification system can help to mitigate the issue; however, beneficiary identification should be improved to minimize exclusion errors and systematically check that eligible people are enrolled.

Second, there is international and Cambodia-specific evidence of informal payments being deeply embedded in the healthcare system [22, 39]. HEF beneficiaries may be unaware that they should not pay, and thus do so. They may also pay for care to show appreciation or because they believe they will receive better services.

The decision to seek health care and the choice of provider is based on individuals' assessing and maximizing utility [40]. The exemption of user fees should act as an incentive to use public healthcare services, particularly among the poor who have higher demand elasticity. However, no evidence was found of increased utilization of public facilities among the poorest quintile compared to other groups. This suggests that the reduction of more than half of OOPE (compared to third wealth quintile patients) is insufficient to counterbalance the (perceived) negatives of public providers or the (perceived) positives of other providers. In addition, OOPE was found to have a negative effect on public sector care-seeking: a $0.5 \%$ decrease in probability with every US\$10 increase in OOPE $(\mathrm{p}<0.02)$. Therefore, the reduction of OOPE is expected to improve access, and in turn increase demand for and use of public services.

Provider choice is also likely affected by other factors which were not accounted for. Provider reputation and patient satisfaction has been shown to be critical to attracting new patients [41]. In addition, low utilization of public facilities has been attributed to low perceived quality, an important determinant for public healthcare seeking among HEF beneficiaries [40, 42].

\section{Conclusion and Recommendations}

The results from this study show that HEF is not yet fully reaching its intended impact of removing OOPE as a barrier to access among the poor. In addition, free access to healthcare should incentivize utilization of public services; however, this study was unable to isolate such an effect among patients from the poorest wealth quintile. This suggests that the reduction of more than half of OOPE is not sufficient to increase public provider access among poor patients (compared to higher income patients). In addition, unobservable factors, such as quality perception or lack of information among beneficiaries. are likely influencing provider choice. Finally, as about $36 \%$ of people under the national poverty line do not hold an Equity card, enrolment exclusion is also likely impeding access to healthcare among the rural poor.

Service quality perceptions should be explored to better understand their effect on provider choice and aid in promoting use of public facilities. Access to healthcare can be strengthened with policy directives focused on increasing beneficiary information to further reduce OOPE. For example, current and new ID Poor households should be briefed on benefits and procedures to access the free care. Mass media and community mobilization activities can be used to promote community awareness about the user fee exemption. Existing systems used to verify services and possible payments by patients can be strengthened.

As mentioned, exclusion errors among the poorest can be reduced by relaxing the inclusion criteria and extending population coverage to vulnerable groups presently excluded. This should include second and third wealth quintile, informal sector households whose out-of-pocket health care costs exceed capacity-to-pay [32].

Patient demand is increasingly considered the key to driving improvements in healthcare service provision [43]. Social health protection schemes should be complimented with other health financing interventions demonstrating increased public health facility utilization and decreased OOPE when combined with HEF [38, 36]. Finally, monitoring of health service access- specifically service utilization, OOPE, and quality- should be strengthened by integrating appropriate indicators into national monitoring and evaluation systems.

\section{Acknowledgements}

The authors would like to thank the Cambodia Ministry of Planning, Institute of Statistics for providing the 2016 CSES data set which enabled the completion of this assessment. We would also like to acknowledge technical review provided by Erik Josephson, Health Economist, World Health Organization Cambodia country office, and Shreeshant Prabhakaran, Health Financing Technical Advisor, Health Policy Plus. Sokcheng Phay, Social Protection Specialist of the General Secretariat for the National Social Protection Council, provided technical review and validated key assumptions about ID Poor. Their comments contributed to the technical quality of this publication. Finally, we recognize Molly Cameron and Jim Cameron, Health Policy Plus, who provided editorial review to improve the overall readability of the paper.

\section{Funding}

This study was completed in part with financial support from the United States Agency for International Development (USAID)/Cambodia under the Health Policy Plus (HP+) project, Cooperative Agreement No. OAA-A-1500051, technical support to the Cambodian Ministry of Economy and Finance, National Social Protection Counsel General Secretariat. The information, analysis, conclusions, and recommendations of this study are not official U.S. 
Government information and does not necessarily represent the view or positions of the U.S. Agency for International Development. Submission of the article for publication was the sole decision of the authors.

\section{References}

[1] UN, "Transforming Our World: The 2030 Agenda for Sustainable Development," United Nations, New York, 2015.

[2] D. Hogan, G. Stevens, A. Hosseinpoor and T. Boerma, "Monitoring universal health coverage within the Sustainable Development Goals: development and baseline data for an index of essential health services," Lancet Glob Health, vol. 6, p. e152-68, 2018.

[3] RAND Corporation, "Health Care Access," 2019. [Online]. Available: https://www.rand.org/topics/health-careaccess.html. [Accessed 12 May 2019].

[4] D. Evans, J. Hsu and T. Boerma, "Universal health coverage and universal access," Bulletin of the World Health Organization, vol. 91, pp. 546-546A, 2013.

[5] M. Thiede, P. Akweongo and D. McIntyre, "Exploring the dimensions of access," in The economics of health equity, McIntyre D, Mooney G, editors., Cambridge, Cambridge University Press, 2007, p. DOI: $10.1017 /$ CBO9780511544460.007.

[6] M. Gulliford, J. Figueroa-Munoz, M. Morgan, D. Hughes, B. Gibson, R. Beech and M. Hudson, "What does 'access to health care' mean?," Journal of Health Services Research and Policy, vol. 7, no. 3, pp. 186-188, 2002.

[7] D. Peters, A. Garg, G. Bloom, D. Walker, W. R and W. Brieger, "Poverty and Access to Health Care in Developing Countries," Annals of the New York Academy of Sciences, vol. 1136, no. 1, p. doi.org/10.1196/annals.1425.011, 2008.

[8] A. Donabedian, "The quality of care: How can it be assessed?" JAMA, vol. 260, no. 12, p. 1743-8, 1988.

[9] P. Annear, D. Wilkinson, M. Rithy Chean and M. van Pelt, "Study of financial access to health services for the poor in Cambodia," Canberra \& Melbourne: Ministry of Health Government of Cambodia, Cambodian office of the World Health Organization, AusAID and RMIT University, Phnom Penh, 2006.

[10] P. Annear, M. Bigdeli, R. Chhun Eang and P. James, "Study of financial access to health services for the poor in Cambodia," Canberra \& Melbourne: Ministry of Health Government of Cambodia, Cambodian office of the World Health Organization, AusAID and RMIT University, Phnom Penh, 2007.

[11] P. Diehr, D. Yanez and A. Ash, "Methods for Analyzing Health Care Utilization and Costs," Annu. Rev. Public Health, vol. 20, p. 125-44, 1999.

[12] M. Bigdeli and P. Annear, "Barriers to access and the purchasing function of health equity funds: lessons from Cambodia," Bulletin of the World Health Organization, vol. 87 , pp. $560-564,2009$.

[13] W. Van Damme, L. Leemput, I. Ir Por, W. Hardeman and B. Meessen, "Out-of-pocket health expenditure and debt in poor households: evidence from Cambodia," Tropical Medicine \& International Health, vol. 9, no. 2, pp. 273-280, 2004.

[14] WHO, "Evidence to inform policy towards universal health coverage in Cambodia," in World Health Day, Phnom Penh, 2018.

[15] A. Fernandes Antunes, B. Jacobs, R. de Groot, K. Thin, P. Hanvoravongchai and F. Steffen, "Equality in financial access to healthcare in Cambodia from 2004 to 2014," Health Policy and Planning, vol. 33, pp. 906-19, 2018.

[16] WHO, "The Kingdom of Cambodia Health System Review, Vol. 5, No. 2," World Health Organization, Phnom Penh, 2015.

[17] P. Annear, K. Khim, E. Moscoe, T. Jordanwood and T. Bossert, "National Coverage and Health Service Utilization by Health Equity Fund Members, 2004-2015," ADRA Research Report, Phnom Penh, 2016.

[18] M. Noirhomme, B. Meessen, F. Griffith, P. Ir, B. Jacobs, R. Thor, B. Criel and W. Van Damme, "Improving access to hospital care for the poor: comparative analysis of four health equity funds in Cambodia," Health Policy and Planning, vol. 22, pp. 246-262, 2007.

[19] WHO, "Strengthening Domestic Financing Institutions for Universal Health Coverage in Cambodia Situation analysis of health financing policy and implementation (in publication)," World Health Organization, Phnom Penh, 2017.

[20] M. White Kaba, K. Baesel, B. Poch, S. Bun, S. Cerceau, L. Bur, B. Schwarz, O. Keo, R. Tung and K. Cheang, "IDPoor: a poverty identification programme that enables collaboration across sectors for maternal and child health in Cambodia," BMJ, vol. 363, p. doi.org/10.1136/bmj.k4698, 2018.

[21] OECD, "Social Protection System Review of Cambodia," OECD Publishing, Paris, 2017.

[22] T. Kelsall and S. Heng, "Inclusive Healthcare and the Political Settlement in Cambodia," New Political Economy, vol. 21, no. 2, p. 238-255, 2015.

[23] NIS, "Cambodia Socio-economic Survey 2014.," National Institute of Statistics, Ministry of Planning, Phnom Penh, 2015.

[24] P. Deb, E. Norton and W. Manning, Health Econometrics Using Stata, College Station, TX: Stata Press, 2017.

[25] R. Paternoster, R. Brame, P. Mazerolle and A. Piquero, "Using the Correct Statistical Test for Equality of Regression Coefficients," Criminology, vol. 36, no. 4, pp. 859-866. DOI: 10.1111/j.1745-9125.1998.tb01268.x., 1998.

[26] World Bank, "Guidelines for Constructing Consumption Aggregates for Welfare Analysis: Living Standards Measurement Study Working Paper No. 135," World Bank, Washington, D.C., 2002.

[27] K. Xu, J. Klavus, K. Kawabata, D. Evans, P. Hanvoravongchai, J. Ortiz, R. Zeramdini and M. CJL, "Household Health System Contributions and Capacity to Pay: Definitional, Empirical, and Technical Challenges," in Health Systems Performance Assessment: Debates, Methods and Empiricism, edited by Christopher J. L. Murray and David B. Evans, Geneva, World Health Organization, 2003a, p. 533-542. 
[28] A. Deaton, "Understanding Consumption," Oxford University Press, Oxford, 1992.

[29] K. Xu, D. Evans, K. Kawabata, R. Zeramdini, J. Klavus and M. CJ, "Household Catastrophic Health Expenditure: A Multicountry Analysis," The Lancet, vol. 362, no. 9378, pp. 111-117, 2003b.

[30] D. Ghosh and A. Vogt, "Outliers: An Evaluation of Methodologies," in Presented at the Joint Statistical Meetings, San Diego, 2012.

[31] StataCorp, Stata Statistical Software: Release 15, College Station, TX: StataCorp LLC, 2017.

[32] R. J. Kolesar, S. Pheakdey, B. Jacobs, N. Chan, S. Yok and M. Audibert, "Expanding Social Health Protection in Cambodia: an assessment of the current coverage potential, gaps, and social equity considerations.," International Social Security Review, vol. 73, no. 1, in press, 2020 .

[33] K. Tong, "Analsysing Chronic Poverty in Cambodia: Evidence from Panel Data, Working Paper Series No. 66," CDRI, Phnom Penh, 2012.

[34] C. Chhim, S. So, V. Theng and K. Tong, "Understanding Poverty Dynamics: Evidence from Nine Villages in Cambodia, Working Paper Series No. 69," CDRI, Phnom Penh, 2012.

[35] B. Jacobs, C. Men, M. Bigdeli and P. Hill, "Limited understanding, limited services, limited resources: patients' experiences with managing hypertension and diabetes in Cambodia," BMJ Global Health, vol. 2, pp. doi: 10.1136/ bmjgh-2016-000235, 2017.

[36] B. Jacobs, A. Bajracharya, J. Saha, C. Chhea, B. Bellows, S.
Flessa and A. Fernandes Antunes, "Making free public healthcare attractive: Optimizing health equity funds in Cambodia," International Journal for Equity in Health, vol. 17, no. 88, pp. doi.org/10.1186/s12939-018-0803-3, 2018.

[37] G. Flores, P. Ir, C. Men, O. O'Donnell and E. Van Doorslaer, "Financial protection of patients through compensation of providers: The impact of Health Equity Funds in Cambodia," Journal of Health Economics, vol. 32, p. 1180-93, 2013.

[38] T. Ensor, C. Chhun, T. Kimsun, B. McPake and I. Edoka, "Impact of Health Financing Policies in Cambodia: A 20-Year Experience," Social Science \& Medicine, vol. 177, p. 118126, 2017.

[39] T. Ensor, "Informal Payments for Health Care in Transition Economies," Social Science \& Medicine, vol. 58, no. 2, pp. 237-246. DOI: 10.1016/S0277-9536(03)00007-8., 2004.

[40] B. Shengelia, A. Tandon, O. Adams and C. Murray, "Access, utilization, quality, and effective coverage: An integrated conceptual framework and measurement strategy," Social Science \& Medicine, vol. 61, pp. 97-109, 2005.

[41] J. Abraham, B. Sick, J. Anderson, A. Berg, C. Dehmer and A. Tufano, "Selecting a Provider: What Factors Influence Patients' Decision Making?," Journal of Healthcare Management, vol. 56, no. 2, p. 99-116, 2011.

[42] S. Kwon and L. Keo, "Social health protection in Cambodia: Challenges of policy design and implementation," International Social Security Review, vol. 72, no. 2, pp. 97$111,2019$.

[43] E. Smith, R. Brugha and A. Zwi, "Working with Private Sector Providers for Better Health Care, an Introductory Guide," Options and LSHTM, London, 2001. 